\title{
Prevalence and associated risk factor of hypertension among individuals of age 18-59 years in South-eastern Nepal: A cross-sectional study
}

\author{
Prajjwal Pyakurel ${ }^{1}$, Deepak Kumar Yadav ${ }^{1}$, Jeevan Thapa ${ }^{1}$, Nishant Thakur ${ }^{1}$, Pramita Sharma ${ }^{1}$, Niraj \\ Koirala ${ }^{1}$, Suraj Kumar Yadav ${ }^{1}$, Akanksha Chaurasia ${ }^{1}$, Sumit Sharma ${ }^{1}$, June Thapa ${ }^{1}$, Santosh Thapa ${ }^{1}$, Amit \\ Shah ${ }^{1}$, Pratigya Panta ${ }^{1}$, Rajina Shrestha ${ }^{1}$, Arpana Dangi ${ }^{1}$, Bijay Acharya ${ }^{2}$, Ujjwal Pyakurel $^{3}$, Nilambar Jha $^{1}$ \\ ${ }^{1}$ B.P.Koirala Institute of Health Sciences, Dharan, Nepal \\ ${ }^{2}$ Division of General Internal Medicine, Johns Hopkins Hospital and John Hopkins University, School of Medicine \\ ${ }^{3}$ Kantipur Dental College and Research Centre, Kathmandu, Nepal
}

Corresponding Author: Prajjwal Pyakurel

School of Public Health and Community Medicine

B.P. Koirala Institute of Health Sciences, Ghopa Camp ,Dharan, Nepal

Email: prazzwal@gmail.com

Cite this article as: Pyakurel P, Yadav D K, Thapa J, et al. Prevalence and associated risk factor of hypertension among individuals of age 18-59 years in South-eastern Nepal: A cross-sectional study. Nepalese Heart Journal 2019; Vol 16(1), 19-26

Received date: 13 th November 2018

Accepted date: 11th March 2019

Abstract

Background: Hypertension is one of the major risk factors for the rising burden of cardiovascular diseases (CVDs) in developing region. It has also been recognized as one of the major public health problems in the developing countries since the early seventies and the rate is increasing not only in urban areas but in rural areas with low socio-economic condition.

Methods: A cross sectional study was conducted in Jogidaha Village Development Comittee(VDC) and Triyuga Municipality of Udaypur district of South-Eastern Nepal. A total of 430 participants of age 18-59 years were selected. Semi-structured questionnaire (WHO NCD STEPS instrument) was used to collect information on demographic variables and associated risk factors with use of show cards. Clinical and anthropometric measurement were done. Primary outcome was prevalence of hypertension. Bivariate and multivariate analysis were performed to show strength of association among various risk factors with hypertension.

Results: The prevalence of hypertension was found to be $25.1 \%$. Prevalence of overweight and obesity was found to be $49.8 \%$. Hypertension was significantly associated with age (AOR=1.09, CI $1.05-1.10$ ) and gender (male $>$ female; $\mathrm{AOR}=2.12, \mathrm{CI}=1.22-3.68)$. Similarly, increased waist-hip ratio(7.12; CI 2.87-17.67), alcohol consumption(OR=2.82, $\mathrm{CI}=1.77-4.52)$, and use of tobacco products $(\mathrm{OR}=1.8, \mathrm{CI}=1.02-3.20)$ showed significant association with hypertension.

Conclusion: There is high prevalence of hypertension in rural districts of South-Eastern Nepal. A community-based preventive approach with early detection and treatment and life-style modification is needed to reduce the burden of disease and make sustainable changes.

Keywords: Hypertension, Risk factors, Rural Nepal.

DOI: https://doi.org/10.3126/njh.v16i1.23894

\section{Introduction}

Hypertension (HTN) among cardiovascular diseases (CVDs) is one of the major components of non-communicable disease and is emerging as a major health problem throughout the world. ${ }^{1}$ About $1 / 4$ th adults worldwide are estimated to have high blood pressure. ${ }^{2}$ It is expected that non-communicable diseases will account for 7 out of every 10 deaths in the developing country with respect to half at present. ${ }^{3}$ Hypertension is one of the major risk factors for the rising burden of CVD in developing region. It has also been recognized as one of the major public health problem in the developing countries since the early seventies. ${ }^{4}$ The silent killer has a potential contribution for heart attacks, strokes and kidney failure. ${ }^{5}$ A study revealed that $69 \%$ of people who had a first heart attack and $77 \%$ of people who had a first stroke had co-existence of high blood pressure. ${ }^{6}$ Similarly, hypertensive persons are more predisposed to develop to a modern day epidemic, diabetes. ${ }^{5}$

@Nepalese Heart Journal. Nepalese Heart Journal retains copyright and work is simultaneously licensed under Creative Commons Attribution License CC - BY 4.0 that allows others to share the work with an acknowledgement of the work's authorship and initial publication in this journal. 
The early systemic HTN study in Nepal was done in early eighties by Mrigendra Samjhana Medical Trust. ${ }^{7}$ The then used World Health Organization (WHO) criteria $(160 / 95 \mathrm{mmHg})$ were used to diagnose HTN. ${ }^{8}$ The prevalence of HTN at that period in different sector of the country was found to be $5.3 \%$ in mountains, $6 \%$ in rural Kathmandu, $8.1 \%$ in terai plains and $9.9 \%$ in urban Kathmandu. ${ }^{7}$ Similarly study done by Vaidya et al. in Dharan municipality of Eastern Nepal showed the prevalence of HTN to be $22.7 \% .{ }^{9}$ Studies had shown that the prevalence of HTN in adult population was around $20 \%$ in urban population. ${ }^{10}$ Survey done in the Sunsari district of eastern Nepal in the early nineties showed the prevalence of HTN to be $5.1 \%$ in adult. ${ }^{11}$ A study done by author himself in 2012 among industrial workers in the eastern Nepal showed the prevalence of HTN to be $33.6 \% .{ }^{12}$ The rate of hypertension and its complications are decreasing in developed countries whereas it is increasing in developing countries. ${ }^{13-16}$ Although hypertensive illness is more prevalent in urban areas; it is also seen in people of rural areas with low socioeconomic condition. ${ }^{16-17}$

However, awareness, treatment and control rates are very poor $^{18}$ among the people of rural South-eastern Nepal. This study aims to estimate the prevalence and associated risk factor of hypertension among people of age group of 18-59 at in Udayapur district in Sagarmatha zone of southeastern Nepal.

\section{Materials and methods}

A cross sectional study was conducted in Jogidaha VDC and Triyuga municipality in Udaypur district of South-Eastern Nepal from 27th November -10th December 2016. Jogidaha VDC has 9 wards, with population of 6,665 and 1,451 household and Triyuga municipality has 17 wards with population of 70,000 and 15,926 household and is the largest municipality of Udaypur district. All the residents of Jogidaha VDC and Triyuga municipality in Udayapur district of age 18-59 years were taken as a sampling frame. We randomly selected 4 wards from both the study site and went to individual houses and performed convenient sampling. In case where more than one member of the age group were present in the household, we selected the youngest member of the family. In case of a diagnosed case of HTN in that family, we prioritized hypertensive cases for assessment.

Individuals of age 18-59 years, residing in Jogidaha VDC and Triyuga municipality of Udayapur district of South-Eastern Nepal were included in the study. Those who were pregnant, mentally disabled, and who refused to give consent were excluded from the study.

\section{Sample Size}

In a similar study from the available literature, ${ }^{19}$ the prevalence of hypertension in age group $\geq 18$ was $20.4 \%$. Taking Permissible Error (PE) at $20 \%$, the sample size (n) is 391 . Considering $10 \%$ non-response rate the total sample size was taken 430 .

$\mathrm{n}=\mathrm{Z}^{2} \mathrm{PQ} / \mathrm{L}^{2}$,

where $\mathrm{P}=20.4, \mathrm{Q}=(100-20.4), \mathrm{L}=20 \% \star 20.4$

Therefore, we get, $\mathrm{n}=391$

Adding $10 \%$ of calculated sample, we get, final sample size to be $391+40=431 \sim 430$

\section{Methods of Data Collection}

The data was collected using a semi-structured questionnaire that was used to elicit information from each study participant for the following variables:

(i) Socio-demographic characteristics such as age, ethnicity, marital status, education and occupation; (ii) Lifestyle-related factors such as dietary habits, salt intake, physical activity, tobacco and alcohol consumption;

Each question was structured to gather as much information as possible without increasing the duration of the interview, which usually lasted about 30 minutes.

Blood pressure was measured with an aneroid sphygmomanometer. Participants were asked to sit quietly and rest for 15 minutes with legs uncrossed. Three readings of the systolic and diastolic blood pressure were obtained, which were taken at the start, at the middle and at the end of the interview (with at least 3 minutes rest between each reading). The mean of the second and third reading was calculated. Hypertension was defined as having systolic blood pressure $\geq 140 \mathrm{~mm} \mathrm{Hg}$ and/ or diastolic blood pressure $\geq 90 \mathrm{~mm} \mathrm{Hg}$ during the study, or being previously diagnosed as having hypertension determined by sighting documentation such as a treatment record book or by the history of the participant taking medicine for high blood pressure. ${ }^{20}$

Height was measured in meter. Standing height was measured with the subject standing upright. Heels were slightly separated touching the vertical board and the weight borne evenly on both feet. Heels, buttocks and scapulae were brought in contact with a vertical surface such as wall. The head was so positioned that the subject looked directly forwards with the Frankfurt plane (the line joining floor of external auditory meatus to the lower margin of orbit) and the bi-auricular plane being horizontal. The head piece was firmly kept over the vertex to compress the hair. The height was then recorded using measuring tape..$^{21}$

Weight was taken using bathroom scale. The scale was kept on a flat surface and the subject was requested to step on it on bare feet without holding on to anything. It was validated on daily basis with known weights. ${ }^{22}$

Waist and hip circumferences were measured with the subject standing keeping arms by the sides and asked to breathe normally. The following points were marked on the right side: (i) the subcostal margin in the mid-axillary line, (ii) the highest point of the iliac crest in the mid-axillary line. The center of these two points was marked. At this point the waist circumference was measured with a measuring tape. The measurement was made up to the nearest millimeter. Adequate care was taken to ensure that the subject was breathing normally at the time of measurement. ${ }^{23}$ Hip circumference was measured at the level of the greater trochanters with the subject standing and breathing normally in a manner similar to that during measurement of the waist circumference. ${ }^{23}$

\section{Analysis}

All data were entered in Microsoft XP Excel spread sheet and converted into SPSS (Statistical Package for Social Sciences) Version 17 program for statistical analysis. Data was summarized using frequency distribution tables, cross tabulation, pie chart for presentation of data. The significance of proportion was used by examining Chi-square test. Multivariate analysis was done using logistic regression. The probability of significance was set at $5 \%$ level of significance at $95 \%$ confidence interval.

\section{Ethical Consideration}

This study was conducted after the approval of submitted proposal, by the Departmental Research Unit which is a part of Ethical Committee of BPKIHS. Approval for conducting the study was obtained after informed consent from the study participants. 


\section{Operational definition}

Municipality: Municipality is town with a minimum population of 20,000 (10,000 for those within hilly regions) It has minimum annual income of NPR 40 lakhs, and is semi-urban area possessing electricity, road, drinking water, communication and similar other basic facilities. ${ }^{24}$

VDC: A village development committee (VDC) in Nepal was the lower administrative part of its Ministry of Federal Affairs and Local Development. Each district had several VDCs, similar to municipalities but with greater public-government interaction and administration. There are currently 3,157 village development committees in Nepal. Each VDC was further divided into several wards depending on the population of the district; the average being nine wards. The Village Development Committee (VDC) was dissolved on March 10, 2017 to be replaced by Gaunpalika (Rural-multiplicity). ${ }^{24}$

Janajati: Janajati/Adivasi is the collective term for the indigenous peoples of mainland South Asia and a large percentage of the Nepalese population. Population belonging to the ethnic minority belong to this group in Nepal. Ethnicity is based on the caste system. There are 120 castes and languages in Nepal. It is complex to analyze the caste and ethnicity and their independent effect on health. ${ }^{25}$

Disadvantaged Janjati: The relatively disadvantaged (Janjati) group includes the indigenous groups who are socially and economically marginalized. ${ }^{26}$

Relatively advantaged janjati: Those janjatis who are socially and economically benefited.

Upper caste group: The relatively advantaged category included Brahmin, Chhetri, Thakuri and Sanyasi castes. Ethnicity was based on the caste system. There are 120 castes and languages in Nepal. It is complex to analyse the caste and ethnicity and their independent effect on health. ${ }^{27}$

Professional and semi-professional: Professional-Involved in decision making process, policy, execution e.g. Doctors, senior administrative officers, senior lecturers, professors, college principles, advocates, estate planters, auditors, newspaper editors, expert musicians, architect, managing directors of industrial and business firms, managers etc. Semi-professional-Occupation requiring post high school or college education e.g. engineers, lecturers, insurance inspectors etc.

Skilled and semi-skilled: Skilled worker-Complicated work requiring long training e.g. carpenter, mason, mechanic, car driver, telephone operator etc. Semi-skilled worker-Work requiring some training e.g. assistant operator or electrician, factory workers, laboratory attendant, bookbinder, waiter or bearer, etc. $^{28}$

\section{Results}

The mean age \pm S.D. of the participants was $35.35 \pm 11.751$ years with most of the participants $(26.3 \%)$ falling under the age group of 18-25 years. Among them, $74.2 \%$ were female. Most of them $(85.6 \%)$ were married. Around half of them (46.5\%) came from upper caste groups while the least $(2.1 \%)$ from relatively advantaged Janajati group. Similarly, around one-fourth (25.8\%) had completed their secondary level education while only $13.7 \%$ were found to be illiterate. About $47.0 \%$ of the total participants were unskilled workers while $25.3 \%$ were farmers, $14.0 \%$ were skilled and semi-skilled manpower, $7.2 \%$ were professional and semi-professional manpower and $6.5 \%$ were unemployed.

Table 1: Socio-demographic characteristics of the Participants $(\mathrm{n}=430)$ :

\begin{tabular}{|c|c|c|}
\hline $\begin{array}{l}\text { Socio-demographic } \\
\text { Characteristics }\end{array}$ & Frequency & Percentage \\
\hline \multicolumn{3}{|l|}{ Age: } \\
\hline i) $18-25$ & 113 & 26.3 \\
\hline ii) $26-33$ & 99 & 23.0 \\
\hline iii) $34-41$ & 78 & 18.1 \\
\hline iv) $42-49$ & 69 & 16.0 \\
\hline v) $50-59$ & 71 & 16.5 \\
\hline \multicolumn{3}{|l|}{ Sex: } \\
\hline i) Male & 111 & 25.8 \\
\hline ii) Female & 319 & 74.2 \\
\hline \multicolumn{3}{|l|}{ Marital status: } \\
\hline i) Never married & 49 & 11.4 \\
\hline ii) Married & 368 & 85.6 \\
\hline iii) Others & 13 & 3.0 \\
\hline \multicolumn{3}{|l|}{ Ethnicity: } \\
\hline i) Dalit & 27 & 6.3 \\
\hline ii) Disadvantaged janajati & 164 & 38.1 \\
\hline $\begin{array}{l}\text { iii) Disadvantaged non-dalit } \\
\text { terai caste groups }\end{array}$ & 20 & 4.7 \\
\hline iv) Religious minorities & 10 & 2.3 \\
\hline $\begin{array}{l}\text { v) Relatively advantaged } \\
\text { janajati }\end{array}$ & 9 & 2.1 \\
\hline vi) Upper caste groups & 200 & 46.5 \\
\hline \multicolumn{3}{|l|}{ Education: } \\
\hline i) Illiterate & 59 & 13.7 \\
\hline ii) Informal education & 83 & 19.3 \\
\hline iii) Less than primary school & 24 & 5.6 \\
\hline iv) Primary school completed & 93 & 21.6 \\
\hline v) Secondary school & 111 & 25.8 \\
\hline vi) $+2 / \mathrm{PCL}$ & 47 & 10.9 \\
\hline vii) Bachelor and above & 13 & 3.0 \\
\hline \multicolumn{3}{|l|}{ Occupation: } \\
\hline i) Farmer & 109 & 25.3 \\
\hline $\begin{array}{l}\text { ii) Professional and } \\
\text { semi-professional }\end{array}$ & 31 & 7.2 \\
\hline iii) Skilled and semi-skilled & 60 & 14.0 \\
\hline iv) Unemployed & 28 & 6.5 \\
\hline v) Unskilled & 202 & 47.0 \\
\hline
\end{tabular}


Table 2: Behavioral risk factors of the Participants:

\begin{tabular}{|l|l|l|}
\hline Behavioral Risk Factors & Frequency & Percentage \\
\hline Current tobacco smokers: $\mathrm{n}=430$ & 62 & 14.4 \\
\hline vi) Yes & 368 & 85.6 \\
\hline vii) No & \multicolumn{2}{|l}{} \\
\hline Current smokeless tobacco users: $\mathrm{n}=430$ & 83 & 19.3 \\
\hline iii) Yes & 347 & 80.7 \\
\hline iv) No & \multicolumn{2}{|l}{} \\
\hline
\end{tabular}

Average number of times smokeless tobacco used (per week): $\mathrm{n}=83$

\begin{tabular}{|l|l|l|}
\hline iv) $0-50$ & 64 & 77.1 \\
\hline v) $51-100$ & 15 & 18.1 \\
\hline vi) $>100$ & 4 & 4.8 \\
\hline
\end{tabular}

Ever consumed an alcoholic drink: $n=430$

\begin{tabular}{|l|l|l|}
\hline vii) Yes & $110)$ & 25.6 \\
\hline viii) No & 320 & 74.4 \\
\hline
\end{tabular}

An alcoholic drink within the past 12 months: $\mathrm{n}=110$

\begin{tabular}{|l|l|l|}
\hline viii) Yes & 93 & 84.5 \\
\hline ix) No & 17 & 15.5 \\
\hline
\end{tabular}

Consumed an alcoholic drink within the past 30 days: $\mathrm{n}=93$

\begin{tabular}{|l|l|l|}
\hline vi) & 68 & 73.1 \\
\hline vii) & 25 & 26.9 \\
\hline
\end{tabular}

Largest number of standard alcoholic drink on a single drinking occasion: $\mathrm{n}=65$

\begin{tabular}{|l|l|l|}
\hline i) $1-10$ & 38 & 58.5 \\
\hline ii) $11-20$ & 20 & 30.8 \\
\hline iii) $>20$ & 7 & 10.7 \\
\hline Ate fruits in a typical week: $\mathrm{n}=430$ & \multicolumn{2}{|l}{} \\
\hline i) No fruits per week & 247 & 57.4 \\
\hline ii) $1-2$ days per week & 63 & 14.7 \\
\hline iii) $>2$ days per week & 120 & 27.9 \\
\hline
\end{tabular}

\begin{tabular}{|l|l|l|}
\hline Total servings of fruit: $\mathrm{n}=430$ \\
\hline i) 0 serving & 247 & 57.4 \\
\hline ii) $1-2$ servings & 63 & 14.7 \\
\hline iii) $>2$ servings & 120 & 27.9 \\
\hline
\end{tabular}

Salt added before or during eating food: $n=428$

\begin{tabular}{|l|l|l|}
\hline i) Always & 84 & 19.36 \\
\hline ii) Often & 15 & 3.5 \\
\hline iii) Sometimes & 54 & 12.6 \\
\hline iv) Rarely & 72 & 16.8 \\
\hline v) Never & 203 & 47.4 \\
\hline
\end{tabular}

Salt added in cooking or preparing foods: $n=430$

\begin{tabular}{|l|l|l|}
\hline i) Always & 417 & 97.0 \\
\hline ii) Often & 13 & 3.0 \\
\hline Processed food high in salt: $\mathrm{n}=428$ & \multicolumn{2}{|l|}{} \\
\hline i) Always & 25 & 5.8 \\
\hline ii) Often & 39 & 9.1 \\
\hline iii) Sometimes & 162 & 37.9 \\
\hline
\end{tabular}

\begin{tabular}{|c|c|c|}
\hline iv) Rarely & 108 & 25.2 \\
\hline v) Never & 94 & 22.0 \\
\hline \multicolumn{3}{|c|}{$\begin{array}{l}\text { Too much salt in diet causes a serious health problem or not: } \\
\mathrm{n}=430\end{array}$} \\
\hline i) Yes & 279 & 64.9 \\
\hline ii) No & 76 & 17.7 \\
\hline iii) Don't know & 75 & 17.4 \\
\hline \multicolumn{3}{|l|}{ Lowering of salt in diet: $n=430$} \\
\hline i) Very important & 73 & 17.0 \\
\hline ii) Somewhat important & 107 & 24.9 \\
\hline iii) Not so important & 170 & 39.5 \\
\hline iv) Don't know & 80 & 18.6 \\
\hline \multicolumn{3}{|l|}{ Salt used: $n=430$} \\
\hline i) Salt with two children logo & 421 & 97.9 \\
\hline ii) Others & 9 & 2.1 \\
\hline \multicolumn{3}{|c|}{ Amount of salt consumed: $\mathrm{n}=387$} \\
\hline i) $<5$ g/day/person & 35 & 9.0 \\
\hline ii) $>5 \mathrm{~g} /$ day/person & 352 & 91.0 \\
\hline \multicolumn{3}{|c|}{ Vigorous-intensity activity: $n=430$} \\
\hline i) Yes & 128 & 29.8 \\
\hline ii) No & 302 & 70.2 \\
\hline
\end{tabular}

Number of days in a typical week involving vigorous-intensity activities: $\mathrm{n}=128$

\begin{tabular}{|l|l|l|}
\hline i) 1 day per week & 10 & 7.8 \\
\hline ii) $1-2$ days per week & 26 & 20.3 \\
\hline iii) $>2$ days per week & 92 & 71.9 \\
\hline Moderate-intensity activity: $\mathrm{n}=430$ & \multicolumn{2}{|l|}{} \\
\hline i) Yes & 287 & 66.7 \\
\hline ii) No & 143 & 33.3 \\
\hline
\end{tabular}

Number of days in a typical week involving moderate-intensity activities: $\mathrm{n}=286$

\begin{tabular}{|l|l|l|}
\hline i) $<2$ days per week & 13 & 4.5 \\
\hline ii) $>2$ days per week & 273 & 95.5 \\
\hline
\end{tabular}

Time spent sitting or reclining in a typical day: $n=430$

\begin{tabular}{|l|l|l|}
\hline i) $0-6$ hours & 366 & 85.1 \\
\hline ii) $>6$ hours & 64 & 14.9 \\
\hline
\end{tabular}

While accessing the behavioral risk factors for HTN, it was found that only $14.4 \%$ were current tobacco smokers while $19.3 \%$ were current smokeless tobacco users, most of who (77.1\%) used smokeless tobacco products $0-50$ times per week. Only about $25.6 \%$ of the participants had ever consumed an alcoholic drink out of whom $84.5 \%$ had at least an alcoholic drink within the past 12 months while $73.1 \%$ had consumed an alcoholic drink within the past 30 days. Among the alcoholics within the last 30 days, the largest number of standard alcoholic drink on a single drinking occasion was found to be 1-10 (58.5\%). About 57.4\% used to eat no fruits at all in a typical week while $14.7 \%$ used to eat fruits on 1-2 days per week and $27.9 \%$ on $>2$ days per week. Out of the total 430 participants, only $27.9 \%$ used to have $>2$ servings of fruits. Most participants (47.4\%) never added salt before or during eating food while $97.0 \%$ used to add salt while cooking foods. Only $5.8 \%$ of the participants always consumed processed food high in salt while $37.9 \%$ participants only sometimes 
consumed such food items.

About $64.9 \%$ thought too much salt in diet could cause serious health problem while $17.7 \%$ thought otherwise and $17.4 \%$ had no idea about it. Most of them (39.5\%) thought lowering of salt in their diet was not so important while only $17 \%$, that is the least, thought it was very important. Almost all of them (97.9\%) used salt with two children logo. Out of them, $91.0 \%$ consumed salt $>5$ gram/day while only $9.0 \%$ consumed $<5$ gram/day. Regarding physical activities, only $29.8 \%$ did vigorous-intensity activity, out of them, $71.9 \%$ did such activity $>2$ days in a typical week. Similarly, $66.7 \%$ used to perform moderate-intensity activity, out of them, $95.5 \%$ had been doing such activities $>2$ days in a typical week. Most of them (85.1\%) spent less than 6 hours a day for taking rest while the remaining $(14.9 \%)$ spent more.

Table 3: Physical parameters of the Participants:

\begin{tabular}{|l|l|l|}
\hline Physical Parameters & Frequency & Percentage \\
\hline BMI (for Asian population): $\mathrm{n}=430$ & 56 & 13.0 \\
\hline i) Underweight $\left(<18.5 \mathrm{~kg} / \mathrm{m}^{2}\right)$ & 160 & 37.2 \\
\hline $\begin{array}{l}\text { ii) Increased but acceptable risk } \\
\left(18.5-23 \mathrm{~kg} / \mathrm{m}^{2}\right)\end{array}$ & 140 & 32.6 \\
\hline iii) Increased risk $\left(23-27.5 \mathrm{~kg} / \mathrm{m}^{2}\right)$ & 74 & 17.2 \\
\hline iv) Higher risk ( $\left.>27.5 \mathrm{~kg} / \mathrm{m}^{2}\right)$ & \multicolumn{2}{|l|}{} \\
\hline Waist-Hip Ratio (male): $\mathrm{n}=111$ & 45 & 40.5 \\
\hline i) Normal $(<0.9)$ & 66 & 59.5 \\
\hline ii) Obese ( $\geq 0.9)$ & \multicolumn{2}{|l|}{} \\
\hline Waist-Hip Ratio (female): $\mathrm{n}=319$ & 134 & 42.0 \\
\hline i) Normal (<0.85) & 185 & 58.0 \\
\hline ii) Obese ( $\geq 0.85)$ & \multicolumn{2}{|l|}{} \\
\hline JNC Classification: $\mathrm{n}=430$ & 203 & 47.2 \\
\hline i) Normal & 159 & 37.0 \\
\hline ii) Pre-hypertension & 45 & 10.5 \\
\hline iii) Hypertension stage 1 & 23 & 5.3 \\
\hline iv) Hypertension stage 2 & &
\end{tabular}

While measuring the physical parameters, $13.0 \%$ were found to be underweight, $37.2 \%$ to have BMI under increased but acceptable risk, $32.6 \%$ under increased risk and $17.2 \%$ under higher risk categories according to BMI for South Asian population..$^{29}$ Out of the 111 male participants, $59.5 \%$ were found to be obese while among 319 females, $58.0 \%$ were found to be obese. According to JNC-7 classification, $47.2 \%$ were found to have normal BP, $37.0 \%$ were found to be pre-hypertensive and $10.5 \%$ and $5.3 \%$ were found to be in stage 1 and 2 respectively. ${ }^{30}$ The overall Hypertension cases( self-reported and measured) was found to be $25.1 \%$ as shown in figure 1 .

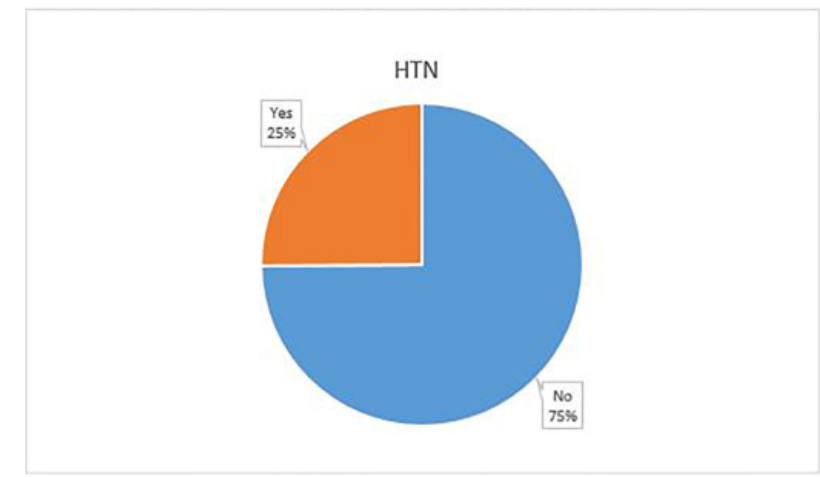

Figure 1: Prevalence of Hypertension (self-reported and measured) $(n=430)$

Taking the age group of $18-25$ years as reference, the people falling under the age group of 26-33 years were 1.51 times more likely to develop HTN (OR=1.51, CI=0.54-4.23). However, it is found to be statistically insignificant. Likewise, the people falling under the age group of 34-41 were 8.02 times more vulnerable to develop hypertension than the reference age group ( $\mathrm{OR}=8.02$, $\mathrm{CI}=3.27-19.64)$, while those of $42-49$ years age group were likely to develop HTN by 13.10 times $(\mathrm{OR}=13.10, \mathrm{CI}=5.33-32.19)$ and those of 50-59 years age group by 13.15 times $(\mathrm{OR}=13.15$, $\mathrm{CI}=.37-32.21$ ). Males were 3.29 times more likely to develop HTN than females $(\mathrm{OR}=3.29, \mathrm{CI}=2.06-5.26)$. Also, current tobacco smokers were more prone to developing HTN than non-smokers by 1.8 times $(\mathrm{OR}=1.8, \mathrm{CI}=1.02-3.02)$.

Likewise, current smokeless tobacco users were 2.93 times more likely to develop HTN than non-users $(\mathrm{OR}=2.93$, CI=1.764.85). Those who had ever consumed an alcoholic drink were more likely to develop HTN by 2.82 times $(\mathrm{OR}=2.82$, CI=1.774.52). Obese males were more likely to develop HTN by 7.12 times $(\mathrm{OR}=7.12, \mathrm{CI}=2.87-17.67)$. Similarly, obese females were more likely to develop HTN by 2.55 times $(\mathrm{OR}=2.55, \mathrm{CI}=1.35$ 4.80). 
Table 4: Association of various Risk factors with hypertension $(n=430)$ :

\begin{tabular}{|c|c|c|c|c|c|}
\hline \multirow[t]{2}{*}{ Variables } & \multicolumn{3}{|c|}{ Hypertension } & \multirow[t]{2}{*}{ Odd's Ratio } & \multirow[t]{2}{*}{ Confidence Interval (CI) } \\
\hline & Yes No & \multicolumn{2}{|l|}{ Total } & & \\
\hline \multicolumn{6}{|l|}{ Age: } \\
\hline i) $18-25$ & $7(6.2)$ & $106(93.8)$ & $113(100)$ & 1 & \\
\hline ii) $26-33$ & $9(9.1)$ & $90(90.9)$ & $99(100)$ & 1.51 & $0.54-4.23$ \\
\hline iii) $34-41$ & $27(34.6)$ & $51(65.4)$ & $78(100)$ & 8.02 & $3.27-19.64$ \\
\hline iv) $42-49$ & $32(46.4)$ & $37(53.6)$ & $69(100)$ & 13.10 & 5.33-32.19 \\
\hline v) $50-59$ & $33(46.5)$ & $38(53.5)$ & $71(100)$ & 13.15 & $5.37-32.21$ \\
\hline \multicolumn{6}{|l|}{ Sex: } \\
\hline i) Female & $60(18.8)$ & $259(81.2)$ & $319(100)$ & 3.29 & $2.06-5.26$ \\
\hline ii) Male & $48(43.2)$ & $63(56.8)$ & $111(100)$ & & \\
\hline \multicolumn{6}{|c|}{ Current tobacco smokers: } \\
\hline i) No & $86(23.4)$ & $282(76.6)$ & $368(100)$ & 1.80 & $1.02-3.20$ \\
\hline ii) Yes & $22(35.5)$ & $40(64.5)^{\prime}$ & $62(100)$ & & \\
\hline \multicolumn{6}{|c|}{ Current smokeless tobacco users: } \\
\hline i) No & $72(20.7)$ & $275(79.3)$ & $347(100)$ & 2.93 & $1.76-4.85$ \\
\hline ii) Yes & $36(43.4)$ & $47(56.6)$ & $83(100)$ & & \\
\hline \multicolumn{6}{|c|}{ Ever consumed an alcoholic drink: } \\
\hline i) No & $63(19.7)$ & $257(80.3)$ & $320(100)$ & 2.82 & $1.77-4.52$ \\
\hline ii) Yes & $45(40.9)$ & $65(59.1)$ & $110(100)$ & & \\
\hline \multicolumn{6}{|c|}{ Waist-Hip Ratio (male): } \\
\hline i) Normal & $8(17.8)$ & $37(82.2)$ & $45(100)$ & 7.12 & $2.87-17.67$ \\
\hline ii) Obese & $40(60.6)$ & $26(39.4)$ & $66(100)$ & & \\
\hline \multicolumn{6}{|c|}{ Waist-Hip Ratio (female): } \\
\hline i) Normal & $15(11.2)$ & $119(88.8)$ & $134(100)$ & 2.55 & $1.35-4.80$ \\
\hline ii) obese & $45(24.3)$ & $140(75.7)$ & $185(100)$ & & \\
\hline
\end{tabular}

Table 5: Multivariate analysis of association between various risks factors and Hypertension:

\begin{tabular}{|l|l|l|l|}
\hline $\begin{array}{l}\text { Significant } \\
\text { Variables }\end{array}$ & $\begin{array}{l}\text { Significant } \\
\text { Values }\end{array}$ & AOR & $95 \%$ CI \\
\hline i) Age & 0.000 & 1.09 & $1.05-1.10$ \\
\hline ii) Sex & 0.008 & 2.12 & $1.22-3.68$ \\
\hline
\end{tabular}

*Adjusted for age, sex, current smoker, smokeless tobacco

Binary logistic regression showed that as age increases, there is an increased risk of developing hypertension by 1.09 time $(\mathrm{AOR}=1.09, \mathrm{CI}=1.05-1.10)$. Similarly, males were more likely to develop hypertension compared to females by 2.12 times $(\mathrm{AOR}=2.12, \mathrm{CI}=1.22-3.68)$.

\section{Discussion}

As per the cross sectional study done in South-Eastern Nepal, the prevalence of hypertension found was $25.1 \%$.The association of behavioral risk factors, biological risks, physical and demographic variations were studied coherently. The outcome of the measured blood pressure $(15.8 \%)$ in the study was in proximity to a similar study done by Dhungana et al, in a similar setting where the prevalence was found to be $12.3 \%{ }^{31}$ However it showed variability with respect to a study done by Adhikari et al following the same study design, which showed the prevalence of $22.3 \%$ in the urban and rural settings of central Nepal. ${ }^{32}$ Similarly, its prevalence was lesser than WHO (27.8\%), ${ }^{33}$ and NCD Steps Survey, $2013(25.7 \%)^{20,33}$ The inconsistency in the finding could be attributed to the predominance of the female participants in the survey, age variability and working population before comparing the outcomes. A uniform standard survey needs to be carried out to know the actual prevalence nationwide.

One of the known behavioral risk factors found in our survey population was smoking and alcohol consumption which was found to be $14.4 \%$ and $25.6 \%$ respectively. The findings of smoking was found to be in proximity with the data of similar study conducted by Aryal et al $(19 \%)^{34}$ and Nationwide NCD Risk Factor Survey,2013 (18.5\% ). ${ }^{20}$ Similarly, the alcohol intake prevalence was $(25.6 \%)$ comparable to the study done by Adhikari et al which is (24\%). ${ }^{32}$ but inconsequent with the STEPS survey 2013 which is $(17.4 \%) .{ }^{20}$ The inconsistency in our findings could be due to the variations in ethnic group, and the predominance of lower socioeconomic class people with $47 \%$ unskilled workers influencing the drinking practices.

The classification of BMI in our study was done following the Asian Classification, ${ }^{35}$ according to which the prevalence of increased risk (BMI:23-27.5 kg/m2)and higher risk (BMI >= $27.5 \mathrm{~kg} / \mathrm{m} 2$ ) was found to be $49.8 \%$. The other study done by Dhungana et al in 2014 showed prevalence of overweight and obesity to be $37.4 \%,{ }^{31}$ that by Nationwide NCD Risk Factor 
Survey, $201325.6 \%,{ }^{20}$ Shrestha et al on 2014 to be $31.9 \% .{ }^{36}$ All of the studies show an increasing trend of BMI. However, most of the studies followed WHO classification unlike the Asian classification implemented in our study.

More than half $(57.4 \%)$ did not take any fruits at all in a typical week. $27.9 \%$ of the respondents had fruits on greater than two days of a typical week. Similar data was found showing the infrequent consumption of fruits in a study done by Dhungana et al which showed that $96.6 \%$ had less than five servings of fruits and vegetables per day. ${ }^{31}$ Daily fruit consumption is less practiced in our setting and people consume fruits mostly during illness, fasting, and religious ceremonies.

The vigorous intensity of physical activity was carried out by $29.8 \%$ of respondents. This is in contradictory with NCD Steps Survey 2013 where $85.0 \%$ had high physical activity. This can be explained by the fact that NCD Steps Survey used MET minutes/week to classify physical activity which was not done in our study. This could be the possible limitation in our study.

Significant association was found with increasing age, gender (male $>$ female; $\mathrm{OR}=3.29, \mathrm{CI}=2.06-5.26)$, tobacco smoker $(\mathrm{OR}=1.8, \mathrm{CI}=1.02-3.20)$, smokeless tobacco users $(\mathrm{OR}=2.93$, $\mathrm{CI}=1.76-4.85)$, alcohol users $(\mathrm{OR}=2.82, \mathrm{CI}=1.77-4.52)$, waist hip ratio (male : $\mathrm{OR}=7.12, \mathrm{CI}=2.87-17.67$; female: $\mathrm{OR}=2.55$, $\mathrm{CI}=1.35-4.8)$ in bivariate analysis. After adjusting for potential confounder it was found that age and sex were found to be statistically significant. This could be co-related to the similar findings in study done by Shrestha et al and Koju et al. ${ }^{1,36}$

\section{Policy and program implications}

This study will add on the existing knowledge of hypertension studies done in different parts of Nepal. However, very few studies has been done in the rural setting of eastern Nepal. As per the new constitution of government of Nepal, country has been divided into seven provincial state and Udaypur district comes under province number 1 . Hence, the present study will help the provincial Government to formulate better policy, awareness and treatment plan for control of hypertension in eastern Nepal.

\section{Strengths}

1. The study has followed a validated questionnaire based on the WHO NCD STEPS instrument version 2.2. So, the study has a standardized approach in data collection.

2. The study was carried out in rural setting in order to find the risk factor for cardiovascular disease and HTN in rural areas.

3 Show cards have been shown to the participants while filling the questionnaire to avoid discrepancies in data collection.

\section{Weaknesses}

1. The study was carried out in only two VDCs so it may not be a representative of the general population of Udayapur district.

2. The results of this study cannot be generalized to individuals older than 60 years in whom the risk factor as well as disease burden is higher than that reported in this population.

3 Information bias by the informants on the consumption of alcoholic beverages, fruits, vegetables and their daily activities.

4 The study might have encountered higher number of house maker (females) and missed the working population as time for data collection was $9 \mathrm{am}-3 \mathrm{pm}$ (i.e., office/working hours).

\section{Limitations}

1. Biochemical assessment: Blood sugar, Total cholesterol, triglycerides, HDL and LDL were not done.

2. Only self-reported hypertension cases were taken into considerations in order to find out the true picture of diagnosed as well as undiagnosed hypertension. Selfreported hypertension cases may already had altered their risk behavior which may not give a true picture of associated risk factors for hypertension.

3 The study population may not be a complete representative of all the people of Udayapur district.

\section{Conclusion}

The prevalence of hypertension in Udaypur district of SouthEastern Nepal was found to be high. Similarly the associated risk factors such as smoking, alcohol, and smokeless tobacco was consumed by higher proportion of the participants. Although the result of the study could not be generalized to whole of the population in Udaypur Districts, it represents similar kind of disease burden and its associated risks factors. Newly formed provincial government should urgently reform policy to aware and treat this emerging problem.

\section{Abbreviation}

PAF: Population Attributable Factor, DALYs: Disability adjusted life years, VDC: Village Development committee, CVD: Cardio-vascular Disease, HTN: Hypertension, WHO: World Health Organisation, BPKIHS: B.P Koirala Institute of Health Sciences PCL: CI: Confidence Interval OR: Odd ratios NCD: Non-communicable Disease BP: Blood Pressure BMI: Basal Metabolic Index, AOR: Adjusted Odds Ratio, PE: Permissible Error, SPSS: Statistical Package for Social Sciences, SD: Standard Deviation, JNC: Joint National Committee, HDL: High Density Lipoprotein, LDL: Low Density Lipoprotein

\section{Competing interests: None}

Funding: There is no funding for this research

Data sharing Statement: We will share unidentified data upon acceptance of the article for publication

\section{Authors' contributions}

PP, DY and JT made substantial contributions to the conception or design of the work or the acquisition, analysis, and interpretation of data for the work. NT and PS revised the work critically. NJ, BA, UP gave final approval for publication. Editing on introduction was done by NK, SKY. Research question was generated by AC. Aims and objectives was created by SS. Materials and methods written by JT. Results were analyzed by ST. Discussions generated by AS, PP. Strengths, weaknesses and limitations written by RS and AD. Final check was done by PP.

\section{Acknowledgements}

We would like to thank BPKIHS, School of Public Health and Community Medicine for providing us the opportunity to conduct this research. We would also like to extend our sincere thanks to the Chief, the Program Coordinator and the Supervising Faculty for providing the guidance and support. Finally, we would like to thank all the participants who gave their consent to be a part of this study.

\section{References}

1. Koju R, Manandhar K, Gurung R, et al. Prevalence of Hypertension in Semi-Urban area of Nepal. Nepalese Heart Journal. 2010 Nov;7(1):35-9.

https://doi.org/10.3126/njh.v7i1.8500

2. Kearney PM, Whelton M, Reynolds K, et al. Global burden of hypertension: analysis of worldwide data. Lancet. 2016 Nov;365(9455):217-23. 
https://doi.org/10.1016/S0140-6736(05)70151-3

3. Murray CJL, Lopez AD. The global burden of disease: a comprehensive assessment of mortality and disability from deceases, injuries and risk factors in 1990 and projected to 2010. Harvard Univ Press. 1996;1:1-35.

4. Fuentes R, Ilmaniemi N, Laurikainen E, et al. Hypertension in developing economies: a review of population-based studies carried out from 1980 to 1998. - PubMed - NCBI [Internet]. [cited 2017 Dec 28]. Available from: https://www.ncbi.nlm.nih.gov/m/pubmed/10826553/\#fft

5. High Blood Pressure: In the context of Nepal I mypublichealthblog.com [Internet]. [cited 2017 Dec 28]. Available from: http://mypublichealthblog.com/?p=162

6. Go AS, Mozaffarian D, Roger VL, et al. Heart disease and stroke statistics-2013 update: A Report from the American Heart Association. Circulation. 2013;127(1).

7. Vaidya A, Pathak RP, Pandey MR. Prevalence of hypertension in Nepalese community triples in 25 years: A repeat cross-sectional study in rural Kathmandu. Indian Heart J [Internet]. 2012;64(2):128-31. Available from: http://dx.doi.org/10.1016/S0019-4832(12)60045-5

8. WHO. Arterial hypertension. Report of a WHO expert committee. 1978. p. 7-56.

9. Vaidya A, Pokharel PK, Karki P, Nagesh S. Exploring the iceberg of hypertension: A community based study in an eastern Nepal town. 2007;5(19):349-359. https://doi.org/10.1179/096992607X217967

10. Maskey A, Sayami A, R PM. Coronary Artery Disease: An emerging epidemic in Nepal. J Nepal Med Assoc. 2003;42:122-4. https://doi.org/10.31729/jnma.807

11. Bhandari GP, Angdembe MR, Dhimal M, et al. State of non-communicable diseases in Nepal. BMC Public Health. 2014;14:23. https://doi.org/10.1186/1471-2458-14-23

12. Pyakurel P, Karki P, Lamsal M, et al. Cardiovascular risk factors among industrial workers: a cross-sectional study from eastern Nepal. J Occup Med Toxicol [Internet]. 2016 Dec 14 [cited 2017 Mar 8];11(1):25. Available from: https://doi.org/10.1186/s12995-016-0109-6

13. Singh RB, Suh IL, Singh VP, et al. Hypertension and stroke in Asia: prevalence, control and strategies in developing countries for prevention. J Hum Hypertens. 2000;14(1011):749-63. https://doi.org/10.1038/sj.jhh.1001057

14. Seedat YK. Hypertension in developing nations in subSaharan Africa. J Hum Hypertens [Internet]. 2000;14(1011):739-47. Available from: https://doi.org/10.1038/sj.jhh.1001059

15. Lenfant C. Can we prevent cardiovascular diseases in lowand middle-income countries? Bull World Health Organ. 2001;79(10):980-2; discussion 983-7.

16. Kumar V, Acanfora $\mathrm{M}$, Hennessy $\mathrm{CH}$, et al. Health status of the rural elderly. J Rural Health [Internet]. 2001 [cited 2017 Dec 28];17(4):328-31. Available from: https://doi.org/10.1111/j.1748-0361.2001.tb00282.x

17. Soylu A, Kavukçu S, Türkmen M, et al. Effect of socioeconomic status on the blood pressure in children living in a developing country. Pediatr Int [Internet]. 2000 Feb [cited 2017 Dec 28];42(1):37-42. Available from: https://doi.org/10.1046/j.1442-200x.2000.01168.x

18. Zachariah MG, Thankappan KR, Alex SC, et al. Prevalence, correlates, awareness, treatment, and control of hypertension in a middle-aged urban population in Kerala. Indian Heart J. 2003;55(3):245-51.

19. Shrestha S, Devkota R. Prevalence of hypertension and its associated risk factors in a sub-urban area of central Nepal. 2016;3(9):2477-86.

https://doi.org/10.18203/2394-6040.ijcmph20163057
20. NHRC Nepal Health Research Council. Non Communicable Diseases Risk Factors: STEPS Survey Nepal 2013. Goverment Nepal Minist Heal Popul Nepal Heal Res Counc. 2013; Available from:

http://nhrc.org.np/.../non-communicable-diseases-riskfactors-steps-survey-nep...

21. Ghai O, Gupta P, Paul V. Ghai Essential Pediatrics. S.D.R. Printers Delhi-94; 2005.

22. Glynn M, Drake W. Hutchinson's Clinical Methods: An Integrated approach to clinical practice. United Kingdom: Saunders Elsevier; 2007.

23. Prabhakaran D, Shah P, Chaturvedi V, et al. Cardiovascular Risk Factor Prevalence among men in a large industry of northern India. Natl Med J India. 2005;(Mar-Apr):59-65.

24. Ministry of Federal Affairs and Local Development I Nepal Government [Internet]. [cited 2018 Mar 3]. Available from: http://mofald.gov.np/en

25. Adibasi Janajati in Nepal I Joshua Project [Internet]. [cited 2018 Mar 3]. Available from:

https://joshuaproject.net/people_groups/20054/NP

26. Bennett L, Dahal DR, Govindasamy P. Caste , Ethnic and Regional Identity in Nepal. 2006

27. Pandey JP, Dhakal MR, Karki S, et al. Maternal and child health in Nepal: The effects of caste, ethnicity, and regional identity . DHS Furth Anal Reports No 73. 2013; (March). Available from: http://dhsprogram.com/pubs/pdf/FA73/FA73.pdf

28. Kuppuswamy's Socioeconomic Scale-Update for July 2015. 2015;(January):1-4.

29. NIH conference. Gastrointestinal surgery for severe obesity. Consensus Development Conference Panel. Ann Intern Med. 1991 Dec 15; 115(12):956-61.

https://doi.org/10.7326/0003-4819-115-12-956

30. Seventh Report of the Joint National Committee on Prevention, Detection, Evaluation, and Treatment of High Blood Pressure (JNC 7) NIH Publication No. 03-5231 May 2003 http://www.nhlbi.nih.gov

31 Dhungana R, S D, Khanal MK, et al. Prevalence of cardiovascular health risk behaviors in a remote rural community of Sindhuli district, Nepal. BMC Cardiovasc Disord [Internet]. 2014;14(1):92. Available from: https://doi.org/10.1186/1471-2261-14-92

32. Adhikari K, Gupta N, Koshy AK. Gender Differences on Risk Factors of Non-communicable Diseases - A Community Based Cross-sectional Study in Central Nepal. J Nepal Health Res Counc. 2014;12(27):89-93.

33. Government of Nepal $M$ of $H$, Population, Nepal), (SOLID S for LIDN, Organization WH. WHO Steps Surveillance: Non-Communicable Disease Risk Factors Survey. 2008;163. Available from:

http://www.who.int/chp/steps/Nepal_2007_STEPS_ Report.pdf

34. Aryal KK, Mehata S, Neupane S, et al. The burden and determinants of non communicable diseases risk factors in Nepal: Findings from a nationwide STEPS survey. PLoS One. 2015;10(8):1-18. https://doi.org/10.1371/journal.pone.0134834

35. Barba C, Cavalli-Sforza T, Cutter J, et al. Appropriate body-mass index for Asian populations and its implications for policy and intervention strategies. Lancet. 2004;363(9403):157-63. https://doi.org/10.1016/S0140-6736(03)15268-3

36. DB Shrestha. Prevalence and Risk Factors of Hypertension in Myanmar. Medicine (Baltimore). 2014;93(21):e100. https://doi.org/10.1097/MD.0000000000000100 